\title{
COMPORTAMENTO DA LECTINA DE SEMENTES DE CANAVALIA BRASILIENSIS MART. DURANTE A GERMINAÇÃO EM PRESENÇA DE LUZ
}

\author{
Benildo Sousa Cavada \\ Clébia Crisóstomo Vieira \\ Lia Magalhães de Almeida Silva \\ José Tadeu Abreu de Oliveira \\ Renato de Azevedo Moreira'
}

\begin{abstract}
RESUMO - A comparação da metabolização da lectina de Canavalia brasiliensis com as demais proteínas de reservas durante a germinação das sementes na presença de luz foi acompanhada através da combinação de dosagem de proteínas solúveis, determinação da atividade hemaglutinante, cromatografia de afinidade em coluna de Sephadex G-50 e eletroforese em gel de poliacrilamida em presença de dodecilsulfato de sódio (SDS) e 2-mercaptoetanol. Os resultados foram comparados com resultados anteriormente obtidos com sementes germinadas na ausência da luz e ficou evidenciado que, mesmo com as plantulas fotossintetizando, a lectina de Canavalia brasiliensis é preservada, sendo metabolizada após as demais proteínas de reserva. Estes dados sugerem também que estas proteínas devam ter funções específicas durante o ciclo vital da planta e não se constituem apenas em proteínas de reserva.
\end{abstract}

Palavras-chave: Lectinas, Canavalia brasiliensis, germinação.

\begin{abstract}
Canavalia brasiliensis seed lectin during germination in the presence of light. The mobilization of the lectin of Canavalia brasiliensis during seed germination, in the presence of light, was studied in comparison with the reserve proteins. Methods employed were determination of soluble protein content, hemagglutinating activity, af finity chromatography on Sephadex G-50 column, and PAGE-SDS. The results showed that the lectin was metabolized later than the reserve proteins suggesting that it may have a special function other than a simple reserve protein.
\end{abstract}

Key words: Lectins, Canavalia brasiliensis, seed germination.

\section{Introdução}

As lectinas são proteínas de origem não imune, capazes de reconheci-

1 - Departamento de Bioquímica e Biologia Molecuar, Centro de Ciências, Universidade Federal do Ceará, Caixa Postal 1065 - CEP 60001 - Fortaleza (CE) Brasil. 
mento específico e ligação reversível a compostos contendo carboidratos e de aglutinar células e glicoconjugados, sem induzir qualquer modificação química nos mesmos (Goldstein et al., 1980; Kocourek e Horejsi, 1983; Barondes, 1988). Distribuídas amplamente na natureza e praticamente em todos os tipos de organismos vivos elas têm sido mais estudadas, entretanto, nos vegetais. $\mathrm{O}$ papel desempenhado pelas lectinas nos vegetais onde são encontradas é, ainda, desconhecido. Especula-se que elas poderiam agir como agentes mediadores da simbiose entre plantas e microorganismos (Hamblin e Kent, 1973; Bohlool e Schimidt, 1974; Dazzo e Truchet, 1983; Diaz et al., 1989), proteger as plantas contra o ataque de patógenos (Mirelman et al., 1975; Jansen et al., 1976; Barkai-Golan et al., 1978; Mishkind et al., 1982; e ainda que seriam simples proteínas de reserva. Uma das maneiras de contribuir para a elucidação do papel endógeno das lectinas vegetais é acompanhá-las durante o ciclo vital da planta e compará-las com as demais proteínas de reserva das sementes. Em sementes de Canavalia brasiliensis Mart., germinadas no escuro, a lectina e demais proteínas de reserva cotiledonárias foram acompanhadas ao longo da germinação, não só pela atividade hemaglutinante como por métodos físico-químicos e imunoquímicos, e foi mostrada uma metabolização diferenciada da lectina em relação às demais proteínas (Moreira e Cavada, 1984). O presente trabalho tem como objetivo acompanhar, através de diferentes métodos, a lectina de sementes de $C$. brasiliensis germinadas na presença de luz e confirmar ou não a sua metabolização diferenciada já observada quando da germinação no escuro, com o intuito de investigar uma provável influência da fotossíntese nesta metabolização.

\section{Material e métodos}

Sementes de $C$. brasiliensis foram coletadas no Estado do Ceará

Condições de germinação.

Após pré-tratamento com ácido sulfúrico concentrado para quebrar a dormência (Moreira e Cavada, 1984) as sementes foram colocadas para germinar em potes contendo vermiculite previamente esterilizada e úmida. As sementes foram imersas na vermiculite, e deixadas germinar na presença da luz, sem a adição de qualquer nutriente (apenas $\mathrm{H}_{2} \mathrm{O}$. destilada e esterilizada) em ambiente saturado de $\mathrm{H}_{2} \mathrm{O}$. A quantidade de água adicionada à vermiculite era o suficiente para não necessitar de regas posteriores. Cotilédones e eixos (plântulas sem os cotilédones) foram coletados a intervalos regulares $(0,3,5$, $7,10,13,17$ e 21 dias após o início da embebição). Amostras foram utilizadas para a determinação de peso fresco e peso seco $\left(110^{\circ} \mathrm{C}\right.$, por 24 horas $)$ e o restante do material coletado foi imediatamente liofilizado, moído e estocado a $4^{\circ} \mathrm{C}$ até uso posterior. 


\section{Extração de proteínas}

Proteínas de farinhas de cotilédones e eixos embrionários coletados foram extraídas com $\mathrm{NaCl} 0,15 \mathrm{M}(1: 10, \mathrm{p} / \mathrm{v})$ durante 4 horas e temperatura ambiente, após o que as suspensões foram centrifugadas a $15.000 \mathrm{X} \mathrm{g}$, a $4^{\circ} \mathrm{C}$ por 20 minutos, e os sobrenadantes utilizados para análises posteriores.

\section{Dosagem de proteínas}

A determinação de proteínas nos diversos extratos e fraçōes foi feita segundo o método de Bradford (1976) utilizando-se albumina sérica bovina como padrão. A absorbância a $280 \mathrm{~nm}$ foi também utilizada para dosar proteínas em eluatos cromatográficos.

\section{Eletroforeses}

Experimentos de eletroforese em gel de poliacrilamida em presença de dodecilsulfato de sódio (SDS) e 2-mercaptoetanol foram desenvolvidos em placas segundo a técnica de Laemmli (1970).

\section{Atividade hemaglutinante}

A atividade hemaglutinante dos diferentes extratos e frações foi determinada como descrito anteriormente (Moreira e Perrone, 1977) utilizando-se soluções de hemácias de coelho. a $2 \%$. A atividade hemaglutinante específica foi expressa como unidade de hemaglutinação (U.H.). $\mathrm{mg}^{-1}$. Uma U.H. foi estabelecida como a concetração de proteínas por ml no último tubo que apresentou hemaglutinação visível.

\section{Cromatografia de afinidade}

Os extratos de cotilédones com diferentes dias de germinação foram aplicados a uma coluna $(1 \times 30 \mathrm{~cm})$ de Sephadex G-50 equilibrada com $\mathrm{NaCl}$ $0,15 \mathrm{M}$ contendo $\mathrm{Ca}^{2+} 5 \mathrm{mM}$ e $\mathrm{Mn}^{2+} \mathrm{mM}$. A coluna foi inicialmente eluída com a solução de equilíbrio e em seguida com a mesma solução contendo glicose $0,1 \mathrm{M}$ ou com tampão glicina- $\mathrm{HC} 10,1 \mathrm{M}, \mathrm{pH} 2,6$ contendo $\mathrm{NaCl} 0,15$ M. As diferentes frações obtidas foram dialisadas contra água, liofilizadas e estocadas para uso posterior.

\section{Resultados e discussão}

As figuras 1, 2 e 3 apresentam os resultados obtidos para peso fresco, peso seco e proteínas solúveis e atividade hemaglutinante em cotilédones de $C$. brasiliensis coletados ao longo da germinação em presença da luz. Não foi detectada atividade hemaglutinante nos eixos. Estes dados confirmam aqueles 


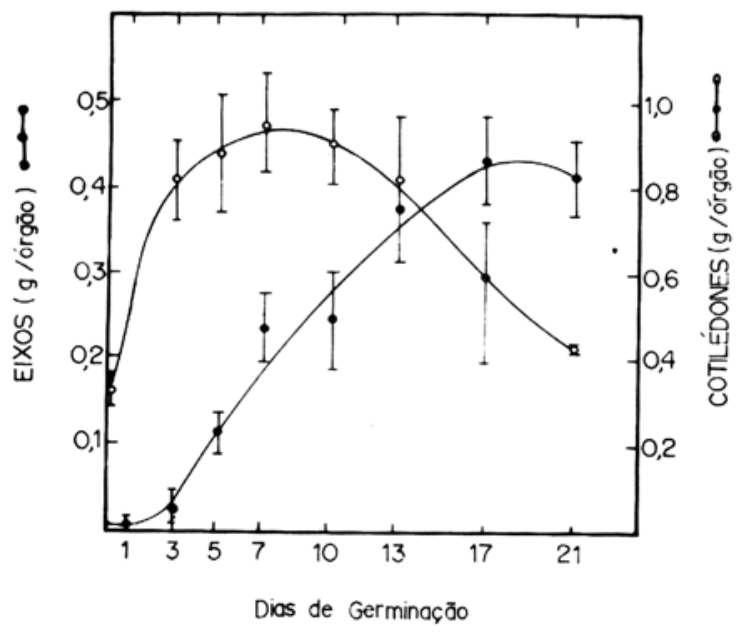

Figura 1 - Peso fresco de cotilédones $(0-0)$ e de eixos $(\bullet \bullet)$ de Canavalia brasiliensis ao longo da germinação na presença de luz.

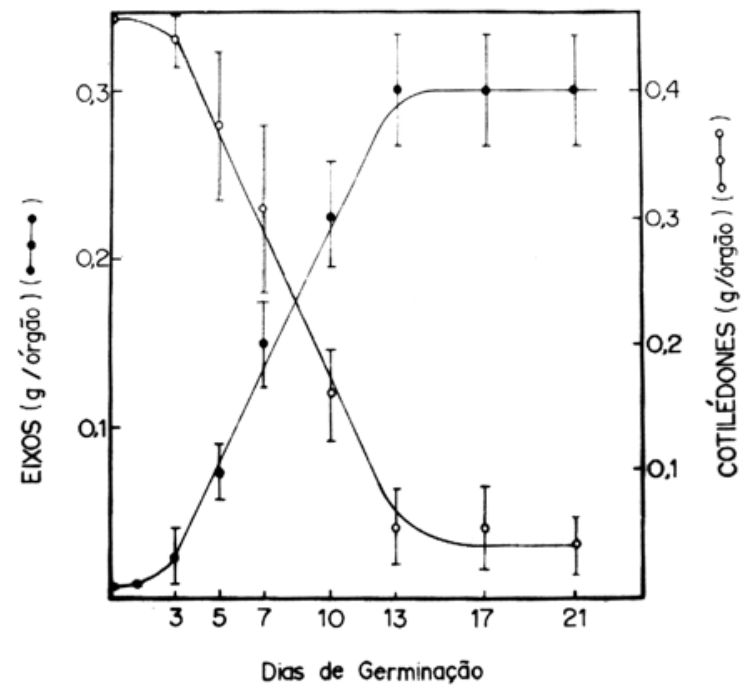

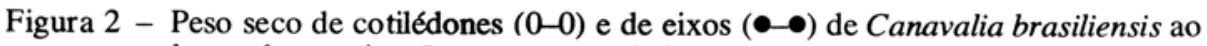
longo da germinação na presença de luz. 


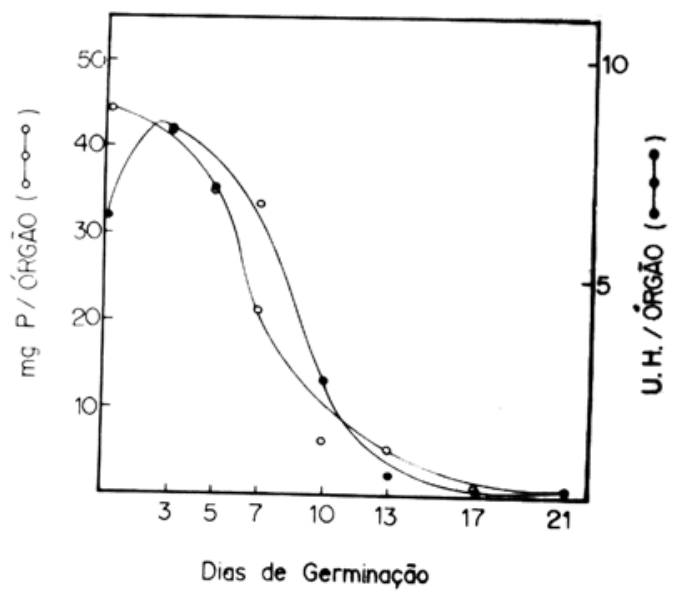

Figura 3 - Contendo protéico $(0-0)$ e atividade hemaglutinante $(\bullet \bullet)$ de cotilédones de Canavalia brasiliensis ao longo da germinação na preença de luz.

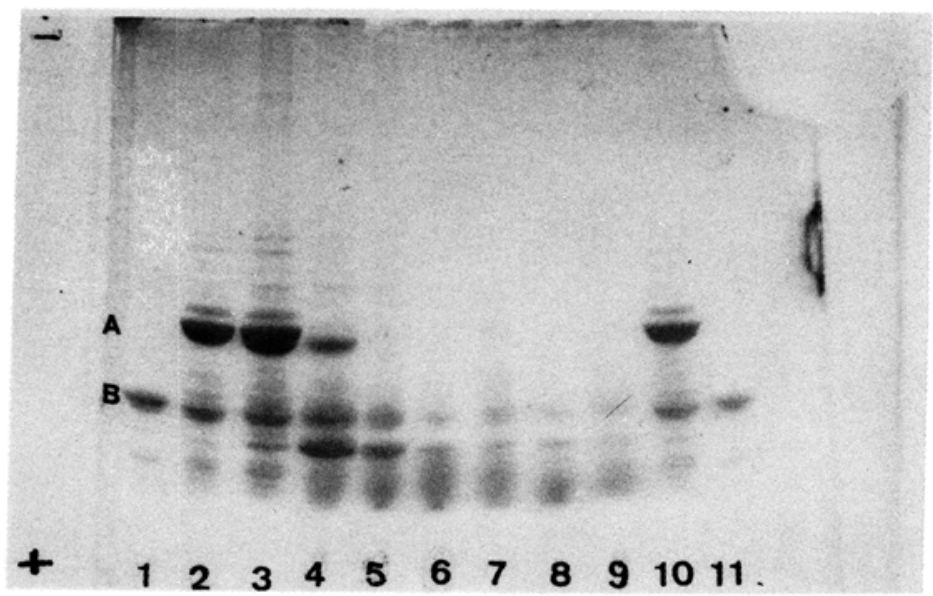

Figura 4 - Eletroforese em gel de poliacrilamida em presença de SDS e betamercaptoetanol. Amostras! 1 e 9, Lectina de Canavalia brasiliensis ( $\left.\mathrm{P}_{\mathrm{III}}\right) ; 2$ a 8 proteínas extraídas de farinhas de cotilédones com $3,5,7,10,13,17$ e 21 dias de germinação na presença de luz. A: $\mathrm{P}_{\mathrm{I}}$; $\mathrm{B}: \mathrm{P}_{\mathrm{III}}$, subunidade de $26 \mathrm{KD}$. 


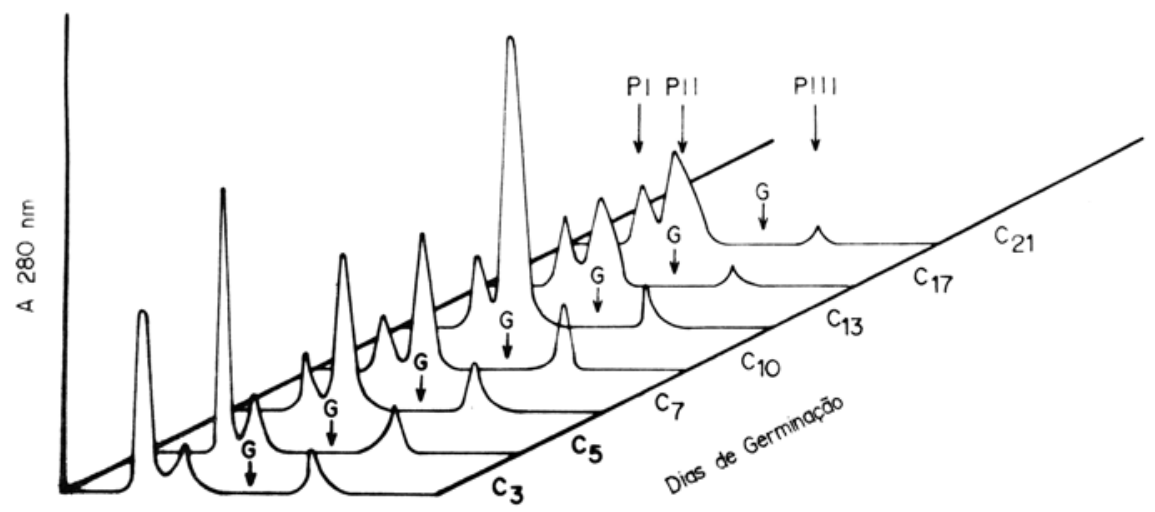

Figura 5 - Cromatografia de afinidade em coluna de Sephadex G-50, de extrato de cotilédones de Canavalia brasiliensis ao longo da germinação na presença da luz. $\left(\mathrm{P}_{\mathrm{I}}\right)$ : proteínas com $\mathrm{PM}$ elevado; $\left(\mathrm{P}_{\mathrm{III}}\right)$ : Lectina. 
obtidos quando as sementes são germinadas no escuro (Moreira e Cavada, 1984), com a diferença de que na germinação na ausência de luz os cotilédones eram exauridos com 15 dias enquanto que na presença da luz, mesmo na ausência de qualquer nutriente externo, isto só ocorreu 21 dias após o início da embebição.

Quando se analisa os teores de proteínas e a atividade hemaglutinante (Figura 3) corrobora-se a idéia já surgida durante o estudo da germinação no escuro, de que a lectina de $C$. brasiliensis desaparece concomitantemente com as demais proteínas de reserva. Entretanto, quando se analisa, por cromatografia de afinidade em coluna de Sephadex G-50 (Figura 5), o comportamento das proteínas solúveis, ao longo da germinação na luz, percebe-se nitidamente que a lectina $\left(\mathrm{P}_{\mathrm{III}}\right)$ é metabolizada mais tardiamente que as proteínas de reserva $\left(\mathrm{P}_{\mathrm{I}}\right)$. Estes resultados são evidenciados por eletroforese das proteínas solúveis dos cotilédones obtidos ao longo da germinação (Figura 4) onde percebe-se que a principal banda representante das proteínas de reserva $\left(\mathrm{P}_{\mathrm{I}}\right)$ desaparece do $5^{\circ}$ para o $7^{\circ}$ dia de germinação, enquanto que a principal banda representante da lectina $\left(\mathrm{P}_{\mathrm{III}}\right.$, subunidade de $\left.26 \mathrm{KD}\right)$ permanece ao longo do período estudado.

Em estudos anteriores foi mostrado que no escuro a lectina de sementes de $C$. brasiliensis é metabolizada de uma maneira diferenciada quando comparada com as demais proteínas de reserva cotiledonárias (Moreira e Cavada, 1984). Esta metabolização diferenciada é confirmada, agora, também na presença de luz, indicando que, mesmo fotossintetizando, esta lectina é preservada. Estes resultados reforçam a idéia de que a lectina de Canavalia brasiliensis não tem função apenas de proteína de reserva e que na realidade ela seria preservada por possuir outra função específica (embora ainda desconhecida) durante o processo de estabelecimento da planta. Após desempenhar seu papel, a lectina seria então metabolizada e utilizada como reserva de aminoácidos.

\section{Referências bibliográficas}

BARKAI-GOLAN R.; D. MIRELAMN \& N. SHARON. 1978. Studies on growth inhibition by lectin of Penicillia and Aspergilli. Arch. Microbiol. 116:119-124.

BARONDES, S.H. 1988. Bifunctional properties of lectins: lectins redefined. TIBS, 13:480-482.

BOHLOO, B.B. \& E.L. SCHMIDT. 1974. Lectins: a possiblle basis for specificity in the Rhizobium-legume root nodule symbiosis. Science, 1985:269-271.

BRADFORD, M.M. 1976. A rapid and sensitive method for the quantitation of microgram quantities of protein utilizing the principle of protein-dye 
binding. Anal. Biochem. 72:248-254

DAZZO, F.B. \& G.L. TRUCHET. 1983. Interactions of lectins and their saccharide receptors in the Rhizobium-legume symbiosis. J. Membr. Biol. 73:1-16.

DIAZ, C.L., L.S. MELCHERS, J.J. HOOYKAAS, B.J.J. LUGTENBERG \& J.W. KIJNE. 1989. Root lectin as a determinant of hostplant specificity in the Rhyzobium-legume symbiosis. Nature 338:579-581.

GOLDSTEIN, I.J., R.C. HUGHES, M. MONSIGNY, T. OZAWA \& N. SHARON. 1980. What should be called a lectin? Nature 285:66.

HAMBLIN J. \& S.P. KENT. 1973. Possible role of phytohemagglutinin in Phaseolus vulgaris L. Nature, 245:28.

JANSEN, D.H., H.B. JUSTER \& I.E. LIENER. 1976. Insecticidal action of the Phytohemagglutinin in black beans on a Bruchid beetle. Science 192:795-796.

KOCOUREK, J. \& V. HOREJSI. 1983. A note of the recent discussion of the term "lectin". In: T.C. BOG-HANSEN, \& G.A. SPENGLER (eds) - Lectins: Biology, Biochemistry, Clinical Biochemistry. Proceedings of the $5^{\text {th }}$ Lectin Meeting. vol. 3, Walter de Gruyter. Berlin-New York.

LAEMMLI, U.K. 1970. Cleavage of structural proteins during the assembly of the head bacteriophage T4. Nature 227:680-685.

MIRELMEN, D., E. GALUN, N. SHARON \& R. LOTAN. 1975. Inhibition of fungal growth by wheat germ agglutinin. Nature 256:414-416.

MISHKIND, M., N.V. RAIKHELL, B.A. PALEVITZ \& K. KENETH. 1982. Immunocytochemical localization of wheat germ agglutinin in wheat. J.Cell. Biol. 92:753-764.

MOREIRA, R.A. \& B.S. CAVADA. 1984. Lectin from Canavalia brasiliensis Mart. Isolation, characterization and behavior during germination. Biol. Plant. 26:113-120.

MOREIRA, R.A. \& J.C. PERRONE. 1977. Purification and partial characterization of a lectin from Phaseolus vulgaris. Plant Physiol. 59:783-787. 